Article

\title{
Analysis and Measures to Improve Waste Management in Schools
}

\author{
Elena Cristina Rada ${ }^{1, *}$, Chiara Bresciani $^{1}$, Eleonora Girelli ${ }^{1}$, Marco $\operatorname{Ragazzi}^{1}$, Marco Schiavon ${ }^{1}$ \\ and Vincenzo Torretta ${ }^{2}$ \\ 1 Department of Civil Environmental and Mechanical Engineering, University of Trento, via Mesiano 77, \\ 38123 Trento, Italy; chiara.bresciani12@gmail.com (C.B.); eleonora.girelli@gmail.com (E.G.); \\ marco.ragazzi@unitn.it (M.R.); marco.schiavon@unitn.it (M.S.) \\ 2 Department of Biotechnologies and Life Sciences, Insubria University of Varese, via G.B. Vico 46, \\ 21100 Varese, Italy; vincenzo.torretta@uninsubria.it \\ * Correspondence: elena.rada@unitn.it; Tel.: +39-0461-282-609 \\ Academic Editor: Raf Dewil \\ Received: 29 June 2016; Accepted: 19 August 2016; Published: 24 August 2016
}

\begin{abstract}
Assessing waste production in schools highlights the contribution of school children and school staff to the total amount of waste generated in a region, as well as any poor practices of recycling (the so-called separate collection of waste) in schools by the students, which could be improved through educational activities. Educating young people regarding the importance of environmental issues is essential, since instilling the right behavior in school children is also beneficial to the behavior of their families. The way waste management was carried out in different schools in Trento (northern Italy) was analyzed: a primary school, a secondary school, and three high schools were taken as cases of study. The possible influence of the age of the students and of the various activities carried out within the schools on the different behaviors in separating waste was also evaluated. The results showed that the production of waste did not only depend on the size of the institutes and on the number of occupants, but, especially, on the type of activities carried out in addition to the ordinary classes and on the habits of both pupils and staff. In the light of the results obtained, some corrective measures were proposed to schools, aimed at increasing the awareness of the importance of the right behavior in waste management by students and the application of good practices of recycling.
\end{abstract}

Keywords: environmental education; separate collection; recycling; municipal solid waste

\section{Introduction}

The Autonomous Province of Trento (PAT) is located in northern Italy and has an efficient waste integrated management system, with the following objectives [1,2]:

- $\quad$ preventing the increase in total municipal solid waste (MSW), also considering the continuous population increase, by pursuing a constant reduction in the per capita production of MSW;

- $\quad$ achieving specific yields of separate collection (SC) for each fraction of waste (current total yield: 75\%) via collecting systems that adopt "wet-dry" separation, and upgrading existing plant facilities to support SC;

- limiting the amount of residual waste to be sent for thermal treatment to about 76,800 t.year ${ }^{-1}$, by reducing the total production of waste in line with the target SC yields;

- $\quad$ selecting technological solutions in MSW facilities for treating different types of waste, in relation to the estimation of emissions and the assessment of the overall environmental impacts. 
SC consists of the sorting of different categories of waste by the users, who are made to feel responsible for the correct disposal of the waste they produce. In the PAT, the citizens are requested to dispose of the waste in dedicated bins, which are meant to separately collect food waste, paper and cardboard, lightweight packaging, glass, and the residual fraction of waste, in addition to special waste (e.g., oil waste, electric and electronic equipment waste, spray cans, etc.) that have to be disposed of in special waste collection centers. The positive effects derived from the maximization of SC and the consequent reduction in waste generation are well-known: recycling of useful materials, resource conservation, energy production and recovery, reduction in toxic releases into the atmosphere and the ground (local impacts), and reduction in greenhouse gas emissions (global impacts) [3,4].

Assessing how the waste produced within schools is managed is crucial. The people who work and/or study in schools produce waste, and the amount of waste generated may be significantly higher than the total amount of waste produced at home, especially in small towns. The organization of SC thus has a very important role. In addition, instilling the right behavior in a child at school often has a positive impact on the attitude of their families and their community towards waste disposal.

In spite of achieving a level of excellence, the waste management system in the PAT still needs to be improved $[1,5]$. Improvements can also be attained by involving the younger generations, so as to nurture conscientious citizens that respect the environment making them aware of the importance of correctly contributing to environmentally sustainable waste management [6-9]. In addition, young people spend most of their time in schools and, thus, their contribution to the overall waste generation is not negligible [10]. Improvements in a waste management system can be achieved through sharing the principles of prevention, accountability, cooperation and transparency, as well as compliance with the criteria of effectiveness, efficiency, economy, transparency, technical and economic feasibility, and the principle according to which the "polluter pays".

This paper contributes to the few studies on MSW management in school institutes [11-13]. The waste production in three schools in the PAT was analyzed: a primary school in the town of Arco, a secondary school, and a high school, the latter two in the town of Riva del Garda. Two additional high schools located in Trento are considered in Section 4 ("Discussion") to compare the results in terms of SC with the high school of Riva del Garda.

The main purposes of this paper are to:

- quantify the current production of waste in the schools;

- assess the awareness of the children/young people of different ages, regarding waste management;

- promote training/education to improve the awareness and the behavior of students with respect to waste management.

Indeed, a quantitative and qualitative dual approach in assessing waste management and sustainable practices in schools is still missing in the current scientific literature. For this reason, this paper is intended to contribute to filling this gap with a discussion of the results based on: (1) the quantification of the SC performance in the different schools under evaluation; and (2) the organizational and educational factors that influence the current situation, and which could improve this situation if appropriate measures were applied at school.

\section{Materials and Methods}

In the schools presented below, students, teachers, and other school employees are requested to properly dispose of the waste depending on the waste nature. If not otherwise specified, all the schools here presented are equipped with bins intended for the collection of the following waste categories: residual waste, paper, lightweight packaging, and organic waste. Paper normally includes sheets from exercise books, newspapers, and cardboard; lightweight packaging includes cans, plastic packaging and polylaminates, mainly from the consumption of snacks and beverages by students; organic waste includes food residues from fruit or snacks eaten at school; any other waste is normally disposed of in 
residual waste bins. Dedicated bins are located in every classroom and in the common areas in the school (e.g., corridors, courtyards). In some cases, scholars are requested to empty the bins of their classroom in the corresponding larger bins in the common areas.

\section{1. "Segantini" Primary School in Arco (Case A)}

The "Segantini" primary school is located in Arco (Figure 1), in a central residential area. In the school year 2011/2012, this institute hosted 280 students (age: 6-10) divided into 14 classes; 11 classes follow a "full-time" schedule, in which the lessons are spread over five days a week, from 8:10 a.m. to 4:10 p.m.; in the remaining 3 classes, the lessons take place only in the morning, six days a week. The school has a canteen, whose waste was not considered in this study, as it is managed directly by the contractor of the food service.

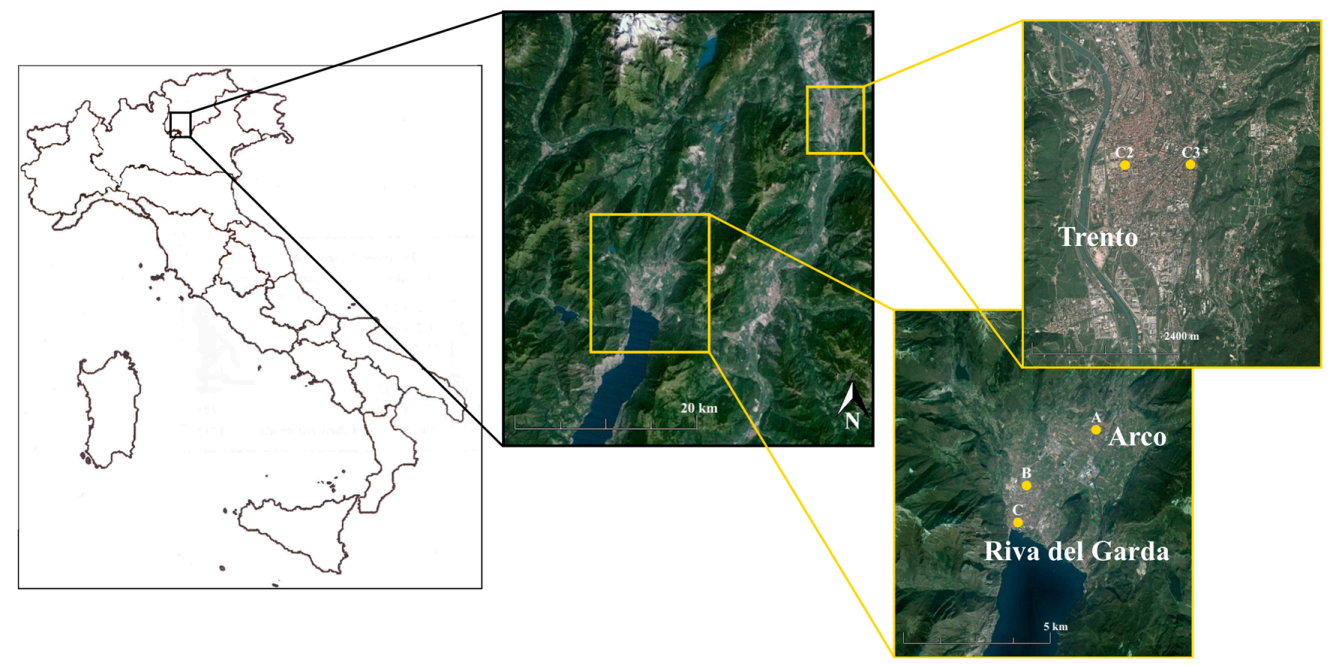

Figure 1. Location of the schools.

In the school building, there are three areas that are meant for waste disposal and that include different waste bins for the collection of the different waste categories the students are asked to dispose of. Such areas are referred to as "ecological areas" in school environments. In this school, one ecological area is present on each of the three floors and four ecological areas are located in the courtyard. All the bins are regularly emptied by the school personnel in a specific area located in the northern part of the building, where dedicated dumpsters are present, which are periodically emptied by the local municipal company that manages waste collection and transport in the PAT. The evaluation of the weekly amount of waste produced was carried out in late May 2012. Firstly, it was necessary to empty all the bins in the common areas of the school and, then, to check the status of the small bins in each classroom. As mentioned above, children were found to be diligent, since they correctly delivered the waste in the bins placed in the corridors, and so most of the small bins located in the classrooms were empty. The same procedure was repeated at the end of the week, in order to measure the entire weekly production of waste. The bins of the various waste categories and of residual waste collected by the cleaners were then weighed. At the same time, the volume of waste was measured by using a bin with capacity of $120 \mathrm{~L}$ and by assessing how much the bin had been filled with waste.

\section{2. "Sighele" Secondary School in Riva del Garda (Case B)}

The "Sighele" secondary school is for kids (age: 11-14) mainly coming from the towns of Riva del Garda, Tenno, and their surrounding villages (Figure 1). In total, in the school year 2011/2012, 324 students were enrolled in this school and were divided into 13 classes. The lessons are distributed over five mornings and two afternoons a week on different days depending on the school section. 
A canteen is present too; however, as in case A, the waste generated in the canteen was not considered, as it is directly managed by the contractor of the food service.

Inside the building, in the corridors, there are four ecological areas and an additional ecological area is located outside in the courtyard. The bins for the different waste categories, located inside the building, are placed outside the main entrance of the corridors, while the external bins are near the gate of the courtyard. The remaining waste is taken to the nearest road dumpster.

The amount of weekly produced waste was evaluated in mid-May 2012 in collaboration with the school cleaners. The quantity of the different fractions of waste was weighed over a period of two weeks. In analogy with case A, the volume of waste was also determined in this case, by assessing the extent to which the $120 \mathrm{~L}$ bins were filled.

\section{3. "Maffei" High School in Riva del Garda (Case C)}

The "Maffei" high school hosts approximately 830 scholars (age: 14-18) from all over the "Upper Lake Garda" (ULG) district and from the towns and villages closest to the provinces of Brescia and Verona. The steady growth in the number of pupils over the years has led to the need for two separate school buildings. In this analysis, only the waste produced in one of the two buildings was considered; this building hosted 28 classes during the year 2012/2013, with a total number of 538 students. Lessons take place six mornings a week, while, in the afternoon, several optional courses or in-depth support activities are provided.

Inside the building, seven ecological areas are located in the corridors and an additional one is located outside in the courtyard. The SC bins are moved outside by the school personnel and are emptied by the municipal company managing waste in the PAT, according to the schedule of collection, while the residual fraction is taken to a nearby waste collection area.

Inside the school, there are no bins for lightweight packaging. Inevitably, this means that recyclable waste is thrown in the residual waste bin.

A quantitative analysis of the weekly produced waste was conducted in mid-February 2013. As in cases A and B, the school staff managed the bags of waste produced during the week, with only one difference: due the bigger size of this school building, two measurements per week were carried out instead of one only: one in the middle of the week and one at the end of the week.

The locations of the schools are presented in Figure 1. The number of students, teachers and other employees in each school is reported in Table 1.

Table 1. Population in schools A, B and C.

\begin{tabular}{cccc}
\hline Kind & School A & School B & School C \\
\hline Students & 280 & 324 & 538 \\
Teachers & 37 & 40 & 57 \\
Staff & 8 & 15 & 18 \\
Total & 325 & 379 & 613 \\
\hline
\end{tabular}

\section{Results}

\subsection{Qualitative Analyses}

The organization of the SC in the primary school (case A) seems to work well: the children regularly empty the bins of each classroom in the bins located in the corridors and the quality of the separated fractions is good. However, the school employees complain about careless behavior of some of the teachers who should be the first to set a good example. The presence of old bins collecting undifferentiated waste led to failures by less careful users and may represent a weak point in the SC organization.

As with case A, the SC in the secondary school (case B) achieved good results too: the students seem to be involved in the project and the school employees also seem satisfied. The quality of the 
different types of waste is good, although errors occasionally occur, such as paper and plastics collected in the same container.

In the case of the high school (case C), the organization of the SC does not always seem to work properly. In fact, the school employees complain about the students not regularly using the bins. In many classrooms the bins are only emptied when they are overflowing, with the result that differentiable waste is also thrown into residual waste bins. The quality of the SC varies greatly from classroom to classroom, but the bins for SC are often used incorrectly. There is also a significant production of glass waste from fruit juice bottles. These are thrown into residual waste bins, since glass is not part of the lightweight packaging and there is no specific bin for glass inside the school.

\subsection{Quantitative Analyses}

\subsubsection{Waste Composition}

In case A, the most important weight fraction (54.4\%) was residual waste, which comes mostly from the cleaning of the classrooms and the school's administrative offices. There was also considerable paper and organic waste, the latter being mainly due to the fruit which is given to the students as a snack. In fact, this school has been involved in the European program "Fruit in Schools", aimed at encouraging the consumption of fruit and vegetables by children and promoting healthier eating habits and more balanced nutrition. The lightweight packaging was the least significant fraction in terms of weight.

Similar to case A, more than half of the waste generated in case B ( $55 \%$ in weight) was residual. The production of paper in case B was very significant, also due to the presence of administrative offices in the school. The weight percentage of the organic waste was very small compared to school A, while the production of lightweight packaging was slightly higher than school A.

With regard to case $C$, the weight percentage of residual waste was higher than the other two schools $(62.3 \%)$. In addition, a considerable percentage of paper $(23.9 \%)$ and a significant fraction of light packaging $(10.7 \%)$ were reported. Conversely, the amount of organic waste measured was quite low. This is due to the fact that the only bin for the collection of food waste is placed in the courtyard, which is not used very often, especially in winter. Some organic waste is therefore collected with the residual fraction.

The results of the quantitative analyses performed in schools A, B, and C are summarized in Table 2.

Table 2. Results of the quantitative analysis undertaken in schools A, B, and C.

\begin{tabular}{|c|c|c|c|c|}
\hline Type of Waste & Weight (kg) & Volume $\left(\mathrm{m}^{3}\right)$ & Density $\left(\mathrm{kg} \cdot \mathrm{m}^{-3}\right)$ & $\%$ Weight \\
\hline \multicolumn{5}{|c|}{ School A } \\
\hline Residual fraction & 34.1 & 0.88 & 38.75 & 54.4 \\
\hline Paper & 12.6 & 0.39 & 32.31 & 20.1 \\
\hline Lightweight packaging & 4.8 & 0.26 & 18.46 & 7.7 \\
\hline Organic & 11.2 & 0.06 & 186.67 & 17.9 \\
\hline Total & 62.7 & 1.59 & & 100.0 \\
\hline \multicolumn{5}{|c|}{ School B } \\
\hline Residual fraction & 37.4 & 0.96 & 38.96 & 55.0 \\
\hline Paper & 20.2 & 0.52 & 39.15 & 29.7 \\
\hline Lightweight packaging & 6.2 & 0.35 & 17.71 & 9.1 \\
\hline Organic & 4.2 & 0.02 & 175.00 & 6.2 \\
\hline Total & 68.0 & 1.85 & & 100.0 \\
\hline \multicolumn{5}{|c|}{ School C } \\
\hline Residual fraction & 73.5 & 1.76 & 41.76 & 62.3 \\
\hline Paper & 28.2 & 0.80 & 35.07 & 23.9 \\
\hline Lightweight packaging & 12.6 & 0.49 & 25.57 & 10.7 \\
\hline Organic & 3.7 & 0.02 & 205.56 & 3.1 \\
\hline Total & 118.0 & 3.07 & & 100.0 \\
\hline
\end{tabular}




\subsubsection{Total and per Capita Waste Production}

Case $\mathrm{C}$ is characterized by the highest production of waste, mainly due to the fact that it hosts many more students than the other two institutes considered in this study (Table 1); an $88.6 \%$ and $61.7 \%$ higher number of people in case $\mathrm{C}$ with respect to cases $\mathrm{A}$ and $\mathrm{B}$, respectively, corresponding to an $88.2 \%$ and a $73.5 \%$ increase in the total production of waste. In case $B$, there is a $16.6 \%$ higher number of people with respect to case $\mathrm{A}$, which led to an $8.5 \%$ increase in waste production. In terms of the production yields of the different waste fractions, the amounts of paper, lightweight packaging, and residual waste increased with the number of people, as expected, while the amount of organic waste decreased. As mentioned above, school A is part of the European program "Fruit in Schools" and is therefore the only school with a significant production of organic waste.

In order to draw comparisons that are independent of the population of each institute, the per capita production of waste was analyzed including all the following school users: students, teachers, school staff, and administrative employees. The per capita production of the different waste fractions analyzed is shown in Table 3.

Table 3. Per capita weekly production of waste in schools A, B and C.

\begin{tabular}{cccc}
\hline Type of Waste & School A $\mathbf{( g )}$ & School B (g) & School C (g) \\
\hline Residual fraction & 104.9 & 98.7 & 119.9 \\
Paper & 38.8 & 53.3 & 46.0 \\
Lightweight packaging & 14.8 & 16.4 & 20.6 \\
Organic & 34.5 & 11.1 & 6.0 \\
Total & 192.9 & 179.4 & 192.5 \\
\hline
\end{tabular}

The smallest per capita production of waste was observed in case B, while the other two schools had almost the same per capita production. The main noticeable difference concerns the per capita production of the organic fraction, which ranged from $34.5 \mathrm{~g}$ in school A to about $6.0 \mathrm{~g}$ in C. With regard to the paper fraction, school A was characterized by the lowest production. The higher values reported in cases $B$ and $C$ are due to the presence of a large number of offices, especially in case $B$. Another reason is the significant provision of newspapers that are read in the classrooms of school C. The per capita production of lightweight packaging fraction increased with the age of the students, which is mainly due to the presence, especially in school $\mathrm{C}$, of vending machines for drinks and snacks, which are absent in case A.

\subsubsection{Comparison between the Schools}

In order to better highlight the different results among the schools, Table 4 reports the percent differences between the three cases in terms of per capita production of waste.

Table 4. Differences between schools A, B and C in terms of weekly per capita production of waste (values expressed as \%).

\begin{tabular}{ccccccc}
\hline Type of Waste & B vs. A & $\begin{array}{c}\text { B vs. A } \\
\text { (without Organic } \\
\text { Fraction) }\end{array}$ & C vs. A & $\begin{array}{c}\text { C vs. A } \\
\text { (without Organic } \\
\text { Fraction) }\end{array}$ & C vs. B & $\begin{array}{c}\text { C vs. B } \\
\text { (without Organic } \\
\text { Fraction) }\end{array}$ \\
\hline Residual fraction & -5.9 & -5.9 & +14.3 & +14.3 & +21.5 & +21.5 \\
Paper & +37.5 & +37.5 & +18.7 & +18.7 & -13.7 & -13.7 \\
Lightweight packaging & +10.8 & +10.8 & +39.2 & +39.2 & +25.6 & +25.6 \\
Organic & -67.8 & +6.2 & -82.5 & +17.7 & -45.5 & +10.8 \\
Total & -7.0 & -5.9 & -0.2 & +14.3 & +7.3 & +21.5 \\
\hline
\end{tabular}




\subsubsection{Comparison between Cases A and B}

In case B, the total production of waste was $7.0 \%$ lower than case A. With regard to the different waste fractions, case B presented a higher production of paper, due to the presence of offices in the building, and of light packaging, while the amounts of residual waste and organic fraction decreased. It is also worth underlining that school B is attended by students for five days out of seven, unlike school A which is also open on Saturday morning.

\subsubsection{Comparison between Cases A and C}

The difference between the per capita production of total waste in case $\mathrm{A}$ and the respective production in case $\mathrm{C}$ was negligible $(+0.2 \%)$. However, the higher amount of residual fraction, paper, and lightweight packaging produced in case $\mathrm{C}$ was evident, while the organic fraction was much lower. The higher production of paper is due to the presence of administrative offices and to the reading of newspapers in the classrooms. The higher presence of lightweight packaging in school C is due to the presence of vending machines selling drinks and snacks, which are consumed by students. If the organic fraction is not considered, the total per capita production was substantially higher in case $\mathrm{C}$ than in case A.

\subsubsection{Comparison between Cases B and C}

The total amount of residual waste and lightweight packaging was higher in school C, while the amounts of paper and organic fraction were lower. In school $\mathrm{C}$ the total production of waste was $7.3 \%$ higher than in school B. When the organic fraction is not considered, the situation described above changes only slightly, due to the low production of food waste in case $C$, which is common in those institutes where there is no canteen service $[14,15]$, and to the fact that food waste was not taken into account in the quantitative analysis of case B. However, food waste generation in canteens can be very high, as demonstrated in a recent study on a primary school [16], where food waste accounted for $45.3 \%$ of the meals served.

\section{Discussion and Proposals}

\subsection{Discussion on Quantitative Results}

The production of residual waste was not only related to the size of the institutes or to the number of people working inside, but also to the activities that are carried out and to the habits and behaviors of students and employees. Our data show that the production of organic waste is not sufficient to justify a specific SC in secondary schools (B and C), while it is justified in primary schools (A). It is probably more useful to improve information on how to separate and collect the other types of waste. In any case, the collected data do not determine whether a more virtuous behavior depends on the age of the students and, thus, on the level of education. This result is in contrast with the findings from a previous study [13], which shows a lower SC yield achieved by the youngest scholars. The higher yield obtained in the present study may be explained with the active role of teachers and school employees in motivating the scholars towards sustainability and good environmental practices. Since no evident differences among age classes were detected, an integrative analysis was carried out to compare the data obtained in case C with the two cases: the "Da Vinci" high school (case C2) and the "Galilei" high school (case C3). School C2 hosts about 1300 students per year. In each classroom, there have been three bins since 2009/2010: one for residual waste, one for paper, and one for lightweight packaging. Other bins, used to collect the same categories of waste, are located in the school corridors. School C3 hosts almost 900 students per year and every classroom is equipped with the same types of bins as school C2. In addition, bins for the collection of paper, lightweight packaging and residual waste are located in the school corridors, as in school C2. 


\subsubsection{Comparison between Case $C$ and Cases $C 2$ and $C 3$}

Considering the data reported in Table 5 , it is clear that the waste production in case $\mathrm{C}$ is higher, both with respect to $\mathrm{C} 2(+67.6 \%)$, and C3 (+17.4\%). The same applies for the different waste fractions, where the biggest difference is with the lightweight packaging $(+108.1 \%)$.

Such high values in school $\mathrm{C}$ are mainly due to the high number of people that are present in the building also in the afternoon, since specialization courses for teachers, also coming from other schools, were happening during the period of measurements, in addition to the normal activities dedicated to students. Moreover, in the afternoon, there were students from buildings where the pupils attend extra classes and from the gym. Consequently, the real number of students was greater than the official one.

Table 5. Differences between schools C, C2, and C3 in terms of weekly per capita production of waste (values expressed as \%).

\begin{tabular}{ccc}
\hline Type of Waste & C vs. C2 & C vs. C3 \\
\hline Residual fraction & +55.3 & +14.1 \\
Paper & +65.7 & +11.3 \\
Lightweight packaging & +108.1 & +19.8 \\
Organic & - & - \\
Total & +67.6 & +17.4 \\
\hline
\end{tabular}

The difference observed in the production of light packaging in school C2 is also due to the low number of vending machines in this institute with respect to the other two schools. With regard to the organic fraction, a specific SC is not active in either case C2 or C3. Given the almost negligible amount of food waste collected in case $C$, this is an acceptable result.

\subsubsection{Comparison with the Daily per Capita Production in the Province of Trento}

It is interesting to compare the contribution of the school institutes with the total production of waste in the province of Trento. Considering the data for the year 2011, every inhabitant equivalent produces about $493 \mathrm{~kg} \cdot \mathrm{year}^{-1}$ of waste [17], corresponding to about $1350 \mathrm{~g} \cdot \mathrm{day}^{-1}$. By dividing the total weekly production of waste measured in the three schools (cases A, B, and C) by the respective number of weekly opening days, about $33 \mathrm{~g} \cdot \mathrm{day}^{-1}$ of waste per capita are obtained, which accounts for $2.5 \%$ of the total daily production for the province of Trento. In addition, schools are not open all year round, thus the actual percentage decreases to about $1.5 \%$.

In view of this, the promotion of SC at school and the education regarding good practices of separating the waste streams produced in schools is of secondary importance with respect to the need to educate children and students in the promotion of good environmental practices at home [18-20], providing their families with good examples. This latter aspect is not negligible, especially in the district which schools A, B, and C belong to, since this part of the province has not yet achieved the SC objectives set by the local government $[1,21]$.

\subsection{Current Environmental Education Initiatives in Schools}

The community of the ULG district proposed a series of environmental education activities in schools for the school year 2012/2013. One of these was carried out by the Ecology Group [22] of the primary school of Tenno (close to Arco) which is working very well in involving children in SC.

\subsubsection{Meetings Proposed by the ULG District}

For the school year 2012/2013, a number of educational meetings concerning the production and the recycling of waste were proposed, in particular: 
- For primary schools:

$>$ two meetings on the paper cycle with a creative laboratory dedicated to the students from the fifth year (last year of primary school);

$>$ the performance of a play at the theatre on the recycling of waste;

$>$ a meeting with local groups of scouts aimed at explaining proper waste collection to children through recreational and educational activities;

- For secondary schools and professional institutes:

$>\quad$ an informative plenary session on the importance of waste reduction and its recycling.

\subsubsection{The Ecology Group of the Primary School of Tenno}

In the primary school of Tenno, teachers have set up an Ecology Group (EG), which consists of a teacher, a janitor, and five children from the fourth year (aged 9 years) [22]. The EG, represented by one of its students, checks the waste produced by the different classes each week, and reports any errors to the remaining students. The EG notes down the performance achieved by each class in terms of efficiency in separating waste, underlining mistakes and/or inappropriate waste disposal. Every month, all classes are checked and the best performance is then rewarded with a diploma. In this way, the quality of the separated fractions is very good.

In addition, the EG uses signs to easily indicate the correct use of the bins. For example, a plastic spoon for residual waste or an aluminum lid of a yoghurt pot for light packaging. This is in order to make immediately clear to children (especially the youngest) what to do and where to throw the litter. The beneficial role of extracurricular activities was documented in a recent study carried out in South Africa [11]. Improvements in the SC yields are then expectable if the activities carried out in the ULG district would be exported and applied elsewhere.

\subsection{Proposals to Improve the SC in School Institutes}

\subsubsection{Critical Issues}

The results of the qualitative and quantitative analyses carried out in this study show that providing schools with adequate material is not sufficient to obtain satisfactory SC yields. The conscious involvement of all the people working and studying inside schools is much more important.

During the weeks of analysis, several critical issues were identified, such as:

- the presence of bins without clear instructions (or no instructions at all) thus leading to the frequent incorrect separation of the waste fractions, such as those that were present both inside and outside school A;

- the lack (in some ecological areas) of the bins dedicated to a particular fraction of waste (e.g., in the courtyard of school C, there was no bin for lightweight packaging);

- the lack of attention in correctly separating waste by teachers and school staff, who should give examples of the correct behavior;

- the lack of a regular emptying of bins located inside the classrooms, especially in school C;

- incorrect application of the SC by the students, due to carelessness or lack of information;

- the presence of additional waste fractions that could be collected separately (e.g., glass in school C) and which are instead disposed of as residual fraction. However, in these cases, the real value in activating a dedicated SC must be assessed.

Furthermore, the high percentages of waste collected as residual fraction $(>50 \%)$ highlighted the wide margins for improvement, although the organic fraction (characterized by high density) is not 
particularly prevalent and, as a consequence, the recycling rate is lower than the rate that can be obtained from household waste. Various guidelines for improving the SC in school buildings were therefore formulated and are presented in the following sections.

\subsubsection{Improvement of Information and Communication}

A dedicated website could be a very useful tool to provide people with information, making all the materials on SC and its organization available to the public. Informative posters for use at home or in various other productive activities could be downloaded and printed, thereby improving the SC throughout the local area and not only in schools. The data on the qualitative and quantitative analyses on each school could be published, a ranking could be established and prizes could also be proposed to the best-performing schools (e.g., guided visits in waste treatment plants, etc.). A webpage enabling all users to ask experts questions regarding any doubts or problems could also be useful.

A key aspect consists in involving scholars in direct educational activities at school. This target could be achieved by training new users and employees to carry out educational projects on waste management and sustainability. Thus, at the beginning of each school year, projects and related operative aspects should be explained to all newcomers.

Questionnaires could be profitably used to find out whether there are any particular problems related to the correct application of waste management inside schools. Through the data collected, the aspects of waste collection management that are not clear could be highlighted and incorrect behaviors could be rectified through dedicated meetings.

In addition, in order to make children further aware of the importance of good practices of waste collection, EGs could be set up in each school, consisting of teachers, students and school employees. The groups could then periodically evaluate the quality of SC and propose further meetings on environmental issues. The positive role of awareness campaigns in improving SC and reducing the generation of waste has been demonstrated by recent studies [23-25].

Considering the fundamental educational role of teachers, each class should have a teacher responsible for carrying forward a project to raise awareness of environmental issues.

\subsubsection{Supplies}

The generation of residual waste can be also prevented with a selection of the goods supplied to the school: an analysis of the goods arriving at school would highlight the quality and quantity of waste that is likely to be produced and specific goods and/or packing materials could be chosen in order to decrease residual waste and packing materials.

\subsubsection{Management and Organizational Issues}

Each class should identify a student responsible for the regular emptying of bins in order to prevent the accumulation of waste and, consequently, avoid incorrect practices: in fact, when the correct bin is full, it may happen that users throw recyclable waste in the bin dedicated to the residual fraction.

A fundamental aspect of the SC organization is to establish who has to take care of placing the bins outside the building (in the case of door-to-door collection) or of emptying bins into ecological areas, particularly when the cleaning service is carried out by an external company. In this case, in the absence of precise tasks not specified in the contracts, the accumulation of incorrect waste may occur.

A person should be made responsible for the management of special waste or, as an alternative, an external company responsible for the removal of special waste (e.g., batteries, toner for printers and copy machines, or laboratory waste).

\subsection{Analysis of the Waste Production}

Qualitative and quantitative analyses of the waste fractions are necessary to calculate the SC yields, in order to determine any incorrect SC and, possibly, to reconsider the size and location of bins. 
To keep the quality of the separately collected fractions at high levels (or to improve it), continuous monitoring by the EG of a school or by the manager of the school complex is desirable. This should focus not only on the bins placed in the corridors, but also in the various classrooms. As already mentioned, the results of these analyses could be published on a dedicated website, so that students are motivated to compete with other classrooms in an attempt to achieve better results.

A quantitative analysis would make it possible to highlight the trends and any improvements (or deterioration) obtained over the years. In addition, a specific analysis on the waste composition of the residual fraction would help identifying the specific types of waste that had not been considered before in the SC organization. Knowing the weekly production of waste would lead to a complete interception of waste and a correct scheduling of the emptying of bins. However, to carry out such an analysis, a week of ordinary educational activities needs to be selected, avoiding public holidays, school assemblies, strikes and other activities that may not be representative of normal school activities.

\section{Conclusions}

The measurements carried out in the three schools showed that the production of waste does not only depend on the size of the institutes (in terms of students, teachers and other employees), but especially on the types of activities carried out in addition to the ordinary lessons and on the habits of the people working and/or studying in the schools.

A comparison between different types of schools is very difficult, but is interesting in terms of understanding what the most important waste fractions to be collected separately are and which fractions are negligible.

The results also showed that the active and ongoing role of teachers is a key factor in achieving good results.

Lastly, the critical issues identified in the three schools allowed establishing guidelines aimed at improving the management and the collection of waste in schools. In addition, it is also crucial to improve the awareness of the people involved, in such a way that the SC of waste becomes part of the normal everyday life, at school, at home, and in the community.

Author Contributions: All authors contributed equally to the research presented in this paper and to the preparation of the final manuscript.

Conflicts of Interest: The authors declare no conflict of interest.

\section{References}

1. Provincia Autonoma di Trento-PAT. Aggiornamento del Piano Provinciale di Smaltimento dei Rifiuti. Available online: http://www.appa.provincia.tn.it/binary/pat_appa/news/PIANO_INERTI.1352891037. pdf (accessed on 15 September 2015).

2. Rada, E.C.; Zatelli, C.; Mattolin, P. Municipal solid waste selective collection and tourism. WIT Trans. Ecol. Environ. 2014, 180, 187-197.

3. Gentil, E.; Christensen, T.H.; Aoustin, E. Greenhouse gas accounting and waste management. Waste Manag. Res. 2009, 27, 696-706. [CrossRef] [PubMed]

4. Gutberlet, J. Cooperative urban mining in Brazil: Collective practices in selective household waste collection and recycling. Waste Manag. 2015, 45, 22-31. [CrossRef] [PubMed]

5. Rada, E.C.; Ragazzi, M. Selective collection as a pretreatment for indirect solid recovered fuel generation. Waste Manag. 2014, 34, 291-297. [CrossRef] [PubMed]

6. Hungerford, H.R.; Volk, T.L. Changing learner behavior through environmental education. J. Environ. Educ. 1990, 21, 8-21. [CrossRef]

7. Joseph, K. Stakeholder participation for sustainable waste management. Habitat Int. 2006, 30, 863-871. [CrossRef]

8. Dururu, J.; Anderson, C.; Bates, M.; Montasser, W.; Tudor, T. Enhancing engagement with community sector organizations working in sustainable waste management: A case study. Waste Manag. Res. 2015, 33, 284-290. [CrossRef] [PubMed] 
9. Al-Khatib, I.A.; Kontogianni, S.; Abu Nabaa, H.; Alshami, N.; Al-Sari', M.I. Public perception of hazardousness caused by current trends of municipal solid waste management. Waste Manag. 2015, 36, 323-330. [CrossRef] [PubMed]

10. Zhang, N.; Williams, I.D.; Kemp, S.; Smith, N.F. Greening academia: Developing sustainable waste management at Higher Education Institutions. Waste Manag. 2011, 31, 1606-1616. [CrossRef] [PubMed]

11. Kanyimba, A.T.; Richter, B.W.; Raath, S.P. The effectiveness of an environmental management system in selected South African primary schools. J. Clean. Prod. 2014, 66, 479-488. [CrossRef]

12. Liz Martins, M.; Cunha, L.M.; Rodrigues, S.S.P.; Rocha, A. Determination of plate waste in primary school lunches by weighing and visual estimation methods: A validation study. Waste Manag. 2014, 34, 1362-1368. [CrossRef] [PubMed]

13. Ward, M.N.; Wells, B.; Diyamandoglu, V. Development of a framework to implement a recycling program in an elementary school. Resour. Conserv. Recycl. 2014, 86, 138-146. [CrossRef]

14. Redman, E.; Redman, A. Transforming sustainable food and waste behaviors by realigning domains of knowledge in our education system. J. Clean. Prod. 2014, 64, 147-157. [CrossRef]

15. Wilkie, A.C.; Graunke, R.E.; Cornejo, C. Food Waste Auditing at Three Florida Schools. Sustainability 2015, 7, 1370-1387. [CrossRef]

16. Byker, C.J.; Farris, A.R.; Marcenelle, M.; Davis, G.C.; Serrano, E.L. Food Waste in a School Nutrition Program after Implementation of New Lunch Program Guidelines. J. Nutr. Educ. Behav. 2014, 46, 406-411. [CrossRef] [PubMed]

17. Passamani, G.; Ragazzi, M.; Torretta, V. Potential SRF generation from a closed landfill in northern Italy. Waste Manag. 2016, 47, 157-163. [CrossRef] [PubMed]

18. Abarca Guerrero, L.; Maas, G.; Hogland, W. Solid waste management challenges for cities in developing countries. Waste Manag. 2013, 33, 220-232. [CrossRef] [PubMed]

19. Tucker, P.; Speirs, D. Attitudes and behavioural change in household waste management behaviours. J. Environ. Plan. Manag. 2003, 46, 289-307. [CrossRef]

20. Eriksson, O.; Reich, M.C.; Frostell, B.; Björklund, A.; Assefa, G.; Sundqvist, J.O.; Granath, J.; Baky, A.; Thyselius, L. Municipal solid waste management from a systems perspective. J. Clean. Prod. 2005, 13, 241-252. [CrossRef]

21. Provincia Autonoma di Trento-PAT. Guida Alle Attività di Educazione Ambientale per le Scuole del Trentino. 2012. Available online: http://www.appa.provincia.tn.it/binary/pat_appa/guida_scuole/ guida04A.1198235753.pdf (accessed on 15 September 2015).

22. Rete Trentina di Educazione Ambientale-RTEA. Educazione Ambientale. 2015. Available online: http: / /www.appa.provincia.tn.it/educazioneambientale (accessed on 15 September 2015).

23. Babaei, A.A.; Alavi, N.; Goudarzi, G.; Teymouri, P.; Ahmadi, K.; Rafiee, M. Household recycling knowledge, attitudes and practices towards solid waste management. Resour. Conserv. Recycl. 2015, 102, 94-100. [CrossRef]

24. Crociata, A.; Agovino, M.; Sacco, P.L. Recycling waste: Does culture matter? J. Behav. Exp. Econ. 2015, 55, 40-47. [CrossRef]

25. Saladié, O.; Santos-Lacueva, R. The role of awareness campaigns in the improvement of separate collection rates of municipal waste among university students: A Causal Chain Approach. Waste Manag. 2016, 48, 48-55. [CrossRef] [PubMed]

(C) 2016 by the authors; licensee MDPI, Basel, Switzerland. This article is an open access article distributed under the terms and conditions of the Creative Commons Attribution (CC-BY) license (http://creativecommons.org/licenses/by/4.0/). 